\title{
Improving Lecturing in Higher Education
}

\section{Vers une amelioration des cours en enseignement supérieur}

\section{CHRIS FUREDY*}

In spite of periodic criticism of lectures as vehicles of learning, courses with regular lecture periods as the major instructional mode remain the predominant feature of undergraduate education in universities and colleges. Consequently, lecturing is a central concern of most programmes for the improvement of teaching in institutions of higher education. An impressive array of formats now exists for "lecture improvement" with individual counselling and the lecture workshop constituting the principal methods.

Individual counselling procedures vary from informal discussions after classroom observation to highly structrued diagnostic procedures utilizing systematically gathered data on course design and lecture delivery. ${ }^{1}$ However, since most "instructional development" programmes are very small relative to the size of the faculty, individual counselling can reach only a few of those who are interested in improving as lecturers. The lecture workshop, varying in length from half a day to three and either standing alone or embedded in a course on university teaching, currently dominates the techniques of lecture improvement. For this reason it is important to scrutinize the workshop approach in the light of general goals for improving lecturing in universities and colleges. In this paper I suggest that lecture workshops tend to concentrate on delivery techniques, whereas a variety of approaches are required for the long-term problems of lecturing. I argue that a lecture improvement programme should maintain a broad perspective on the use of the lecture method, which might include consideration of the design of lecture courses, the variation of teaching methods to achieve desired academic goals, and attention to student "lecture learning skills.". In implementing the eclectic approach, programmes with slim financial resources will need to stimulate self-help and mutual aid among faculty and students.

\section{Limitations of the Lecture Workshop}

Lecturing workshops may include group discussions of the appropriate use of the lecture method, tips on lecture delivery, evaluation simulations, demonstrations of audio-visual techniques and even consideration of alternatives to lecturing. But the component which has aroused the greatest interest is the practice lecturing or microteaching session. Partici-

*Division of Social Science, York University 
pants deliver a 5 - to - 15 minute talk which may be a "mini-lecture" or may represent a segment of a full-length lecture (for instance, the definition of a concept or the explication of a principle). The lecturers may simply lecture "as usual" or they may attempt to practise a particular skill. The talk is videotaped and played back for comment by a small group comprised of workshop participants, with or without the guidance of an educational consultant. Repractice is often included and some three-day workshops have three practice sessions. ${ }^{2}$

Research evidence for the effectiveness of videotape feedback and the lecture workshop in general in promoting long-term improvement is very inconclusive $;^{3}$ nevertheless the videotape session is very frequently rated by participants as the most interesting and most relevant activity of a lecture workshop. ${ }^{4}$ The enthusiasm generated by these procedures suggests that the lecture workshop with practice sessions will remain a major component of most lecture improvement programmes. As more institutions mount workshops, formats are being refined and the lecture workshop bids to become a sophisticated tool in instruc tional development.

But what is this tool used for? What is it that lecture workshops seek to improve? For the most part attention is concentrated on delivery techniques and elementary features of the organization of "the lecture" (or even the mini-lecture) considered as an isolate. This is understandable enough. The predominant conception of lecturing is that of a 50-minute monologue in which responsibility for communication rests with the lecturer. Communicating techniques are usually high on the list of priorities for junior lecturers ${ }^{5}$ for whom most workshops are designed. Delivery and basic organizational behaviours ${ }^{6}$ are relatively uncomplex. They are amenable to observation, analysis, practise and change. They can be "worked on" in a short space of time and dramatic improvements can often be effected. They are to some extent independent of the subject matter of the lecture. The interest in delivery behaviours of the lecturer is fostered by student evaluations which are often designed to assess delivery, with other aspects of a lecture course taking second place. In student responses to open-ended questions, on presentation techniques have been found to predominate. ${ }^{7}$ A good deal of the published research on lecturing is concerned with precisely defined behaviours of the teacher during lecture delivery. ${ }^{8}$ All these factors reinforce the focus upon the lecturer and the lecture.

I do not wish to appear unduly critical of this emphasis, which is both sensible given the needs expressed by those seeking improvement, and practical, given the constraints of workshops. Attaining competence as a public speaker is a legitimate concern and no one would deny that mastery of goodcommunication skills is central to the effective use of the lecture method. It may be time to ask, however, whether delivery skills and lecture organization are significant, long-term problems for most lecturers and to question whether we should concentrate so many of our scarce resources for the improvement of lecturing on their development.

\section{Complex Problems in the Lecture Method}

My experience of teaching in team-taught courses over a period of eight years - which has enable me to observe the complete series of lectures of over 20 of my colleagues ${ }^{9}$ - suggests that the delivery and organization of individual lectures are not persistent 
problems for most lecturers. Most of those who displayed problems in these aspects in their first lectures improved noticeably within a year, without, incidentally, the benefit of explicit counselling on lecture delivery. Assuming that university teachers by and large wish to be competent at delivering lectures, most manage to attain a reasonable level of functioning. The more fundamental organizational and delivery problems are those which appear to derive from the design of a lecture series and the dependence upon the traditional 50 minute "monologue" lecture as the predominant teaching strategy.

Most lecturers have not been exposed to ideas of systematic curriculum design and the choice of teaching strategies according to carefully considered educational objectives. They may have heard of "student-centred" teaching but have little knowledge of findings in psychological and educational research which would enhance their awareness of the student as a learner in the lecture hall. Thus universities and colleges abound with lecturers who plan their lecture courses without thinking through achievable objectives, who rarely consider alternatives to the traditional monologue and who have very little understanding of their students' learning capabilities. For many lecturers, the development of an apparently effective style serves to induce complacency; they become shut off from fresh ideas on teaching methods. ${ }^{10}$

A lecture improvement programme should have the ability to reach such lecturers and to address these more complex aspects of the use of the lecture method. Consequently I believe it is important that a lecture improvement programme avoid being identified merely or even mainly with improvement in delivery technique. Its general, goals should be to encourage thoughtful scrutiny of lecture courses: the design of the lecture series, the use of the lecture within it, the selection of teaching methods for individual lecture periods and the modes of student learning in lectures themselves.

\section{Course Design and Teaching Methods in Lecture Courses}

There is now an extensive literature to draw upon in designing more comprehensive approaches to lecture improvement. The technology of course design is growing rapidly and there are several useful discussions of strategies for course planning which encourage a systematic approach built on clear objectives and variety in teaching methods. One of the most recent and thorough is Teaching Students, by Donald Bligh, G.J. Ebrahim, David Jaques and D. Warren Piper. They present a general model for course planning which may be adapted to the needs of lecture courses. ${ }^{11}$

Bligh's earlier pioneering work, What's the Use of Lectures? remains the most comprehensive treatment of the lecture method as such. It effectively questions the assumption that a lecture should be a monologue delivered to relatively passive students, and provides the rationale for variety within the period by matching differing techniques to goals for student learning (for instance, the design of a lecture to promote thought or to teach attitudes) $)^{12}$.

These perspectives can be made integral to a lecture improvement programme. Some induction courses for new teachers in British universities approach the discussion of lecturing within the context of course design. For example, the Inservice Training Course for University Teachers run by the University of Strathclyde in 1975-76 required participants to prepare a "unit of work" which outlined the way in which they would like to 
give a course, including course aims and objectives, content, instructional methods, feedback and student assessment. In the lecture practice workshop of the course, the mini-lecture was based on a lecture designed within the unit of work. Participants grouped into "tutorials" with a more senior academic as a "tutor" early in the academic year and meetings and individual consultations took place before and after the course itself (which was scheduled at the end of the first term). The course itself contained a session (with readings) on the psychology of learning and lecturers were encouraged to apply learning principles in the design of the course and its lectures. ${ }^{13}$

Some instructional development programmes plan their lecture improvement for departmental target groups rather than individuals. This may shift the emphasis from the individual lecturer and allow consideration of curricular goals. This is the approach preferred by the Division of Studies in Medical Education at the University of Toronto. The programme is described as having four phases: an examination of the objectives of the "instructional programme" (for instance, a course) and of the role of each lecturer within it; the development of plans for improvement (through discussions with faculty and students, workshops, and one-to-one consultations); implementation, and evaluation. Central to the programme is consideration of the lecture "as a component of the total instructional programme". One of the more interesting instruments used to open up discussion is a questionnaire administered to both faculty and students on the functions of lecturing. ${ }^{14}$ Discrepancies often surface between the lecturers's views and those of the students and the resultant discussion between faculty and students may result in a better understanding of and use of the lecture by both.

This systematic approach is not intended to be slavishly followed by a faculty group. The programme is discussed and adapted to the concerns of the department. For instance, some groups may wish to pay more attention to evaluation of their lecture courses in general rather than to the effectiveness of individual lecturers. The outline of the programme serves to alert the group to aspects of lecturing which they may have overlooked. It seems preferable to handle a systematic approach flexibly, as many faculty will react unfavourably to an implication that they are to be "processed" according to an educational consultant's pat formula. ${ }^{15}$

I will return to futher issues in the implementation of improvement programmes later. The aspect I wish to emphasize for the moment is that approaches such as those mentioned, while they may use the lecture workshop and practice session at some stage, employ a variety of means - group discussion, individual consultation, student-faculty discussions, evaluation forms - within a framework which directs attention to course design and the purposes of a lecture series.

\section{Changing Students' "Lecture Learning”}

The concern underlying these more complex approaches to lecturing is course design for student learning rather than the communication skills of the lecturer; nevertheless the lecturer remains, inevitably, the person who is to be "improved". Yet if we are serious about a student-centred philosophy perhaps more consideration should be given to how students' attitudes and behaviour might be changed in the interests of more effective lecture courses. Perhaps some of the most significant improvement in the lecture method 
would come if students improved their "lecture learning" techniques? Knowledge of principles of learning and the development of awareness of cognitive style could be important in students' intellectual development. I remember the impact which studying something of the psychology of learning in a first year undergraduate psychology course had upon my learning techniques. Why should these benefits be reserved for psychology students? There are a variety of ways in which important ideas on learning could be made available to students -- as a class handout or reading, in a lecture, in a series of brief assignments, even in a self-instructional module which all students in a course would be encouraged to complete. Ways of enhancing student effectiveness in a whole range of skills pertinent to lectures - listening, note-taking, critical thinking, question asking, exemplification - could be devised and designed into undergraduate courses.

Most campuses in Canada have centres or programmes which provide training or counselling in study skills, including the ones mentioned, but only a minority of students make use of these resources. The programmes are inevitably very general in order to be appropriate to a range of students and subject matters. They are often mechanistic in design - one thinks of the "SQ3R method" - and not readily adaptable to differences in learning styles. I suggest that it is more important for the concern for student learning skills to be made integral to at least introductory undergraduate courses in universities. The approach should avoid mechanical rules. The goal should not be to turn each student into an efficient note-taker. It would seem to be important to encourage diversity and awareness of differences in style. Students should have the opportunity to develop a variety of learning styles appropriate for different subject matters, lecturers and course goals. Attention need not be confined to student behaviour in the lecture class itself. If a critical factor in learning from lectures is preparation and review ${ }^{16}$, then preparation and review should be made central to course goals and rewards.

A questionnaire at the beginning of a course asking students about their learning goals, their expectations for lectures and the skills they wish to develop could provide a starting point. I have included items on academic skills in a pre-course questionnaire for a small upper-level class: after identifying desired skills, students were encouraged to plan their study and assignments in the light of their goals. ${ }^{17}$ Small exercises built into a course, such as asking students to summarize the assumptions underlying a lecture or to develop questions appropriate to ask in lectures can be useful. Having students work in "question groups" to develop questions ahead of a lecture generates more, and more penetrating, questions. ${ }^{18}$

Why should students not participate in lecture workshops so that practice lectures could be delivered to real rather than surrogate students? Students can also participate in videotape freedback sessions. One of the most beneficial exercises I have tried was to invite students to view and discuss a videotape of one of my lectures. My notes, as well as their notes and evaluations completed at the end of the live lecture all provided information for the session. Such discussions may increase the insight of both lecturers and students, insight into styles of learning as well as course goals.

It might be objected that such procedures would transform every lecture course into a "psychology of learning" course. Obviously, we must find ways of achieving improvement that are not heavy-handed and repetitive. If understanding the subject matter of the course remains the primary concern, it should be possible to encourage a better understanding 
of the ways lecturer and students can co-operate in making the lecture course a more effective method for higher education.

\section{Self-Help and Mutual Aid for Lecture Improvement}

Thus I would argue that lecture improvement should be broadly conceived, based on an understanding of the purposes a lecture series might serve in a university course. This understanding should take into account what we know of the psychology of learning and of effective teacher and student behaviours. A lecture improvement programme should be designed to touch the important components of the lecture as a mode of instruction. If a sense of the complexity and potential of the lecture method can be maintained as a constant backdrop, more specific workshops and training programmes will find their appropriate place in the programme. The argument for diversity in teaching methods is as partinent to lecture improvement as to learning in general: lecturers are individuals who learn in many different ways and, if they decide upon improvement, they will probably prefer to select from a variety of methods. Each approach has its advantages and limitations and each can be used with wise judgment as to its appropriateness for the teachers, the students, the subject matters and the institutions concerned.

It is easy to make such reassuring statements, but for institutions which have slim resources for formal instructional development programmes - perhaps only one faculty member acting part-time and a university committee - the task of providing comprehensiveness and variety may seem to be overwhelming. After all, lecturing is only one among many of the concerns of such programmes. A small programme may have the time and resources to mount only one or two "events" concerned with lecturing as such in any one year. In fact, even institutions with relatively large programmes can provide "formal" activities on lecturing for only a fraction of the faculty who may want them or could benefit from them. Significant changes in the quality of teaching and of lecturing in particular may, in the end, depend as much upon self-help and mutual aid among colleagues as upon a formal programme.

Thus an important role for an instructional development programme is to promote and expand the possibilities of self-help and mutual aid, among both instructors and students. When workshops or courses are held they could be designed to generate mutual aid as an outcome, with minimum monitoring from specialized resource persons. For instance, those attending workshops could agree to form pairs or groups to visit each others' classes and continue to discuss goals and methods. Packages consisting of interesting readings, discussion issues and even workshop formats could be made available to departments or units to encourage group efforts at improvement. Scenarios for simulation exercises in course design could be adapted to the needs of specific departments.

Teaching teams form natural mutual aid groups. Course teams who have developed co-operative techniques (including well-designed course plans, regular comments on each others' lecture, and good student assignments) should be encouraged to report upon their efforts in departmental or instructional development newsletters and to maintain "open door" policies for their colleagues. The University of Michigan's Centre for Research in Teaching and Learning has developed some peer counselling models for graduate student assistants ${ }^{19}$; similar ideas could be extended to faculty. In general, relaxed observation of classes by teachers needs to be encouraged a great deal more. 
Evaluation forms designed to provide appropriate feedback on goals, lecturers' and students' expectations, and students' skills could go a long way towards influencing attitudes and suggesting directions for change. Student councils might be interested in initiating voluntary student discussion groups on lecture learning. The provision of "videotape and view" facilities by media centres with the minimum of fuss for instructors (why not students too?) would encourage self-assessment ${ }^{20}$ One can envisage selfinstructional modules for voice improvement. (There are already useful books with accompanying audio-tapes for this purpose.$^{21}$ ) There are now appearing manuals designed to be used in improvement programmes which can be readily adapted to individual selfhelp or group co-operation. One excellent example is George Brown's Preparing to Teach in Higher Education. ${ }^{22}$ One section, for instance, deals with the use of explanation in lecturing and gives guidelines for running a videotape session with a group of peers. The procedure is elaborated to apply to lecture preparation in general.

Some instructional development programmes produce short papers on important topics. ${ }^{23}$ The literature made available should not be all practical in its orientation. Some faculty begin to reflect upon their teaching methods after reading of the educational principles of respected academics. The collection of essays by Canadian academics edited by Edward Sheffield, Teaching in The University: No One Way, has aroused a great deal of interest in Canada since its publication in $1974 .^{24}$

A special effort should be made to provide the opportunity for creative contributions from faculty and particularly from senior faculty, for it is critical that lecture improvement not be confined to the beginning lecturer. A seminar-discussion series is not difficult to organize. The Teaching and Learning Seminars at York University which are advertised in the campus Daily Bulletin have drawn forth contributions from a wide range of faculty. Contributors are invited to write up their ideas in short essays for publication in a booklet.

A university's committee on teaching or an instructional development office can be instrumental in drawing forth "resource persons" willing to contribute in a variety of ways to a campus programme. A small group of people working gradually but consistently to create exchange relationships can help the development of networks which cross departmental lines. At York in 1976-77, we were able to put together a "resource person list" by contacting those who had made past contributions or shown an interest in the Teaching Skills Programme. Forty-one persons responded representing 28 units in the university within 7 faculties and 6 non-academic units. The list contains brief statements on the backgrounds and interests of the faculty and the ways in which they are prepared to contribute to improve teaching. ${ }^{25}$

In such ways a formal programme can build upon and develop the self-help and mutual aid procedures which already exist to some extent on any campus. The formal programme should aim to create the environment for a broad understanding of the lecture method and the lecture course and to provide as wide a range of resources as possible for teachers and students.

Finally, it is to be hoped that research will augment the efforts suggested here. Research into the improvement of lecturing has drawn upon the studies into effective teacher behaviours or styles and is now beginning to take into account studies of student learning; a further thrust of "improvement research" has been the assessment of formal programmes, workshops and courses. While these lines of enquiry develop, the research horizon should be expanded to include those aspects of improvement which will serve the ends of self- 
help and mutual aid. "Anthropological" studies might reveal the kinds of social and academic environments conducive to the exchange of ideas about teaching, course development and helping relationships among both students and teachers. And we need to gain longitudinal insight into the improving teaching. Undoubtedly developmental studies will not be easy to conduct, but university teachers might be encouraged to reflect upon their development as teachers, to keep log books of teaching ideas and experiences, to preserve student and peer evaluations, course outlines, video-and audio-tapes and so on. ${ }^{26}$ Stable teaching teams could provide developmental peer evaluations. Certainly every effort should be made to generate research and reflection by all who feel they have a contribution to make: our understanding should not wait upon the research conducted by faculties of education and psychology departments.

In the long view, the improved use of the lecture and of the lecture course in universities cannot depend upon the effects of a few workshops on lecturing or the impact of specialists consulting with a few "clients". The faculty and students themselves, acting as individuals, in course and departmental teams, or simply in friendship groups must generate most of the ideas and interactions which will support the more effective use of the lecture. The primary role of an instructional development programme in respect to lecturing should be to keep before the faculty and students an informed and comprehensive view of the lecture and of the teaching and learning methods most appropriate to it. Then, welldesigned workshops and consultations can serve to improve specific aspects of lecturing. In this way, "lecture improvement" will be released from undue concentration on delivery techniques and should be perceived as worthwhile for all who use the lecture course in higher education. 


\section{FOOTNOTES}

1. One of the better known examples in the "teaching improvement process" designed by the Clinic to Improve University Teaching at the University of Massachusetts at Amherst. It has been described as "a systematic, confidential, structured exchange of ideas, perceptions and suggestions between a faculty development consultant, identified by the Clinic as a Teaching Improvement specialist, and an individual faculty member, the purpose of which is to identify the improve teaching strengths and weaknesses". William H. Bergquist \& Steven R. Phillips A Handbook for Faculty Development, Volume 2. Council for the Advancement of Small Colleges, Washington D.C., 1977

2. This was the plan of a 3-day workshop mounted by the University Teaching Methods Unit, University of London, in January 1976. Practice sessions were scheduled on each day. However few of the participants wished to repeat the practice on the third day and so the plan was modified. It is also interesting that at the second practice session a number of participants chose not to repeat their first talk but to prepare another one.

3. For a brief discussion, and evidence on the effects of self-confrontation by video play back, see Donald Bligh, et al. Teaching Students. Exeter University Teaching Services, Devon 1976, pp. 225-226.

4. This has been the predominent response in evaluations of workshops I have organized at York University and for the Ontario Universities Programme for Instructional Development (OUPID). See Report of Workshop for University Teachers organized by OUPID at Guelph University, May 1976.

5. For instance a.study by Margaret King of concerns of teachers attending a training course at Manchester University in 1970-71 revealed that lecturing aroused the most anxiety of the teaching situations they faced and that the delivery aspect of lecturing was considered a problem by a considerable number. Margaret King, "The anxieties of university teachers.", Universities Quarterly 28 (1) (Winter 1973): pp. 69-83.

6. By "basic organizational behaviours" I mean aspects of the design of a lecture such as itemizing important points or recapitulating them.

7. See Peter Morris, The Experience of Higher Education London: Routledge \& Kegan Paul, 1965 for a report of studies of undergraduates at Leeds, Southhampton, Cambridge and Northhampton College of Advanced Technology in which students' comments were found to relate more to technique of presentation than to content.

8. See for instance, Harry G. Murray, "Lecturing: Classroom behaviours of social science lecturers receiving low, medium and high teacher ratings" in OUPID Newsletter 14 (February 1977): pp. 3-5.

9. The courses are interdisciplinary courses in the Division of Social Science, York University. The members of the course team including lecturers and teaching assistants attend all the lectures in the course.

10. In an attempt to counteract the impression that training workshops will pour participating lecturers in the one mold, workshop leaders often stress the need for each lecturer to develop his or her own "style", thus reinforcing the idea that there is one style compatible with a lecturer's personality. Exeter University Teaching Service, Devon, n.d.

11. Components of the model which are to be taken into account in course planning are: needs and objectives, assessment, student selection, course construction, teaching methods, administration and assessment of teaching.

An up-to-date bibliography on course design is contained in Sally Shake Gaff, Conrad Festa, Jerry G. Gaff, Resource Notebook. Project on Institutional Renewal Through the Improvement of Teaching, Washington, D.C., 1976.

12. D.A. Bligh, What's the Use of Lectures?, Penguin, 1972. This is, unfortunately, currently out of print but it is possible that Penguin will reprint it.

13. University of Strathclyde, "Inservice Training Course for University Teachers, 1975/76. Course Information." Mimeo.

14. Richard G. Tiberius, "Workshop on the Lecture Method for Teachers of Biochemistry." Mimeo. and DSME (U. of T.), Instructional Development Programme. "Lecturing." Mimeo. 


\section{Chris Furedy}

15. This is an objection which has been expressed to the highly structured diagnostic process of the University of Massachussetts (Amherst) approach.

16. See Donald Bligh ibid., pp. $38-40$ and Joln McLeish, The Lecture Method. Cambridge Institute of Education, Cambridge, 1968, p. 48.

17. For instance, one item on the questionnaire read:

"During this course would you like to develop further any of the following skills: ability to lead discussions; ability to participate in discussions; project planning; critical skills; analysis; use of primary materials; preparation and use of visual aids; essay writing; preparation of bibliographies; lecturing; preparation of synopses; preparation of abstracts; others?" It is interesting that 2 of 12 students checked "lecturing" as a skill they wished to learn. Video-tapes of classes provided one source of feedback on skills.

18. I have done this but only on special occasions such as guest lectures. Buzz groups can also be used during lectures to generate questions.

19. The scheme was devised by Stanford Ericksen, using teaching assistants in a psychology course. Ericksen's Motivation for Learning: A Guide for the Teacher of the Young Adult, contains a brief, general comment. University of Michigan Press, Ann Arbor, 1974, pp. 226-232.

20. There is considerable debate about self-assessment. Some have argued that since instructors typically assess their courses more favourably then do their students on certain items, self-assessment is a limited instrument. But there is evidence that when self-assessment is coupled with learning about aspects of higher education, it becomes more valid. Stephen F. Foster. "The effects of a course in post-secondary instruction on university instructors' self-evaluation - two approaches." Paper presented at the 1974 Annual Meeting of the Canadian Psychological Association. Self-assessment instruments are being refined. They vary from check-list rating scales such as that developed by Ray Simpson at the University of Illinois ("Tools for Teacher Self-Evaluation") to more extensive kits such as the Instrucional Analysis Kit developed by Janet G. Donald and Margaret Penney at the Centre for Learning and Development, McGill University.

21. For example, Cicely Berry, Your Voice and How to Use It Successfully. London: George G. Harrap, 1975.

22. Forthcoming, Metheun, 1977. One chapter, "Explaining and Lecturing: some Guidelines" has been distributed by the Nottingham University Teaching Service. The text provides a method of analysing and constructing explanations in a microteaching workshop.

23. To give just a few examples, Duncan Harris of the University of Bath's Educational Services Unit has prepared a series of "brief introductions" for distribution to faculty, including one entitled "How do I know whether my lecture/course is effective?" and the Advisory Centre for University Education at the University of Adelaide has produced a more detailed item on "The Lecture". The University of Michigan's Memo to the Faculty has an issue on "The Lecture", 30 (1968).

24. Kingston: McGill-Queen's University Press, 1974. This is a collection of 24 essays by Canadian university teachers who were identified as excellent in a study of effective teachers as perceived by students.

25. "Resource Persons for Instructional Development." Mimeo. Downsview: York University, (January 1977). Compiled by Chris Furedy and Janette Baker.

26. Detailed reflections by university teachers of their teaching include books such as that by $\mathbf{J}$. Axelrod, The University Teacher as Artist, Jossey-Bass, San Francisco, 1973. Axelrod documents changes in his teaching styles and philosophies over a period of years, largely in seminar classes. 